\title{
Influence of Anti-Stress Preparations and Vitamins on the Growth, Development and Productivity of Phasants
}

\author{
Shafiga Topchiyeva ${ }^{1 *}$, Ramiz Madatov ${ }^{1}$ and Lamiyya Yildiz $^{2}$ \\ ${ }^{1}$ National Academy of Sciences of Azerbaijan, Institute of Zoology, Baku \\ ${ }^{2}$ Tokat Gaziosmasha University, Department of basic medical sciences/Physiology, Turkey \\ *Corresponding author: Shafiga Topchiyeva, National Academy of Sciences of Azerbaijan, Institute of Zoology, Baku
}

\section{ARTICLE INFO}

Received: 幽 June 08, 2021

Published: June 22, 2021

Citation: Shafiga Topchiyeva, Ramiz Madatov, Lamiyya Yildiz. Influence of Anti-Stress Preparations and Vitamins on the Growth, Development and Productivity of Phasants. Biomed J Sci \& Tech Res 36(4)2021. BJSTR. MS.ID.005891.

\begin{abstract}
The article presents data from experimental studies of the effects of anti-stress drugs and a complex of vitamins on pheasants grown in the vivarium of the Institute of Zoology of the National Academy of Sciences of Azerbaijan. The objects of research were Caucasian - Phasianus colchicus and emerald - Phasianus versicolor pheasant, using pheasant obtained by incubating eggs from experimental birds. As a result of experimental studies, a positive effect of anti-stress drugs and a complex of vitamins on the safety and development of pheasants was revealed. An increase in the safety of the experimental groups of pheasants with the use of an anti-stress preparation and a complex of vitamins was established, which was $6.5-20.1 \%$ higher, and live weight - by $7.5 \%$, respectively, compared with the control group of birds. Mass indicators of pheasants grown in artificial conditions (g) were experimentally established with the use of succinic acid and a complex of vitamins. As a result, the safety value of pheasants was revealed using succinic acid and a complex of vitamins, which was 7.25-22.5\% higher, and live weight $-8.2 \%$, respectively.
\end{abstract}

\section{Introduction}

Our studies are devoted to the artificial breeding of two subspecies of pheasants (Caucasian pheasant - Phasianus colchicus, emerald pheasant - Phasianus versicolor). A feature of these studies is that Caucasian and emerald pheasant is a representative of our wild fauna, which is partially involved in agricultural production.

World production of fowl meat of all kinds is, according to literature is about 1 million tons. More than $90 \%$ of its importers are Europe and the United States. The consumption of fowl meat per capita in France, Switzerland, Germany is approaching $1 \mathrm{~kg}$, in Norway - $2 \mathrm{~kg}$, and in Sweden - 3, and in recent years there has been an increase in its consumption. In our republic, such data are not available, so we can assume that consumption is minimal. In view of the fact that the available resources of wild birds are limited, and existing populations of fowl are depleted, in the future the fowl market will largely depend on its breeding in captivity. At present, the governments of many countries of the world are encouraging the development of fowl-producing farms. There is relatively little data on the postembryonic development of pheasants, since their young growth is very mobile immediately after hatching. All studies were carried out either on domesticated forms or on wild species bred in captivity [1-3]. Data on the post embryogenesis of subspecies of the common pheasant are limited by a statement of live weight of adult birds or by some morphometric indicators [4-6]. Although pheasant growth is an important issue, there are several publications containing information on body weight and morphometry of pheasants at different ages. Body weight and some biometric characteristics of pheasant chickens, measured as early as the $3^{\text {rd }}$ week of life, can be used as predictors of future body weight and size $[7,8]$. Thus, we can state that there is relatively little data on the postembryonic development of pheasants, since their young growth is very mobile immediately after hatching. 


\section{The purpose of the Research}

Based on the foregoing, the purpose of these studies was to study the effect of anti-stress medications and a complex of vitamins on the growth, development and productivity of pheasants.

\section{Research Material}

The studies were conducted in the vivarium of the Institute of Zoology of ANAS in 2018 - 2019. The objects of research were the Caucasian and emerald pheasant, while the pheasant obtained from the incubation of eggs from experimental birds was used.

\section{Research Results}

Pheasants quite successfully adapted to various conditions of keeping. In our experiments, pheasants were kept in cells, starting from a day old and for a maximum of two months. For the entire duration of the experiment, no adverse effects on pheasants of the conditions of being in cellular conditions on the mesh floor were noted. Negative moments include injuries when birds, trying to fly up in fright, broke their heads, when pheasants got their feet stuck in the grid of the floor of the cage, due to imperfections in the design of the cells. It should be noted that with the pheasants in the cells being kept in the room, their only noticeable drawback was the less feathering of young animals and the disheveled tail feathers in adult males. Juvenile molting did not proceed as vigorously as when kept outdoors and young animals were not feathered well enough. Apparently, this is explained by a more "sparing" temperature regime for growing young animals indoors. We used anti-stress medications (phenozepam, succinic acid and a complex of vitamins) in experiments on pheasants, which increased the safety of young animals and positively influenced their growth. The mass indicators of pheasants grown under artificial conditions using an anti-stress drug and a complex of vitamins are presented in the Table 1. In the experiments, the safety of the livestock of pheasants of the experimental groups was revealed in comparison with the control groups; while the safety of pheasants was 6.5-20.1\% higher, and live weight - by $7.5 \%$, respectively. Better results were obtained with the use of succinic acid, with the use of the latter it was possible to completely prevent the death of pheasant from pecking. As can be seen from the data in Table 2, the safety of pheasants was $7.25-22.5 \%$ higher, and live weight - $8.2 \%$, respectively. Based on the obtained experimental data and analyzing the growth rate curves of pheasants, it can be noted that the highest growth rate is observed in the first 10 days, further an increase in the growth rate is noted, reaching its maximum on the $20^{\text {th }}$ day. In the next ten days, the growth rate increases significantly, then again stabilizes to 40 days and then gradually decreases over the entire remaining period of growth. Relative growth reaches a maximum of 90 days after hatching. Thus, the analysis of data on the growth and development of pheasant chicks allows us to conclude that special attention should be paid to the organization of proper feeding in the first two weeks after the birth of the chicks, when their rapid growth and development is observed.

Table 1: The mass indicators of pheasants grown in artificial conditions (g) using an anti-stress drug and a complex of vitamins.

\begin{tabular}{|c|c|c|c|c|}
\hline \multirow{2}{*}{ Age (days) } & \multicolumn{3}{|c|}{ Pheasants } \\
\cline { 2 - 5 } & \multicolumn{2}{|c|}{ Caucasian } & Control & Emerald \\
\cline { 2 - 5 } & Control & Experiment & $21,5 \pm 0,15$ & $23,1 \pm 0,20$ \\
\hline Conclusion & $17,1 \pm 0,07$ & $18,4 \pm 0,05$ & $26,1 \pm 0,40$ & $28,1 \pm 0,50$ \\
\hline 5 & $24,5 \pm 0,41$ & $26,3 \pm 0,34$ & $39,5 \pm 0,65$ & $42,5 \pm 0,55$ \\
\hline 10 & $37,3 \pm 0,52$ & $40,1 \pm 0,45$ & $85,2 \pm 1,44$ & $91,62 \pm 1,75$ \\
\hline 20 & $84,1 \pm 1,50$ & $90,4 \pm 1,20$ & $143,0 \pm 2,60$ & $153,7 \pm 3,80$ \\
\hline 30 & $142,1 \pm 3,10$ & $152,8 \pm 4,20$ & $377,1 \pm 12,60$ & $405,4 \pm 9,60$ \\
\hline 60 & $370,5 \pm 16,20$ & $398,3 \pm 21,10$ & $995.5 \pm 19,10$ & $1070.2 \pm 21,10$ \\
\hline
\end{tabular}

Table 2: The mass indicators of pheasants grown in artificial conditions (g) with the use of succinic acid and a complex of vitamins.

\begin{tabular}{|c|c|c|c|c|}
\hline \multirow{2}{*}{ Age (Days) } & \multicolumn{3}{|c|}{ Pheasants } \\
\cline { 2 - 5 } & \multicolumn{2}{|c|}{ Caucasian } & Control & Experiment \\
\cline { 2 - 5 } & Control & Experiment & $21,5 \pm 0,15$ & $23,3 \pm 0,18$ \\
\hline Result & $17,1 \pm 0,07$ & $18,5 \pm 0,06$ & $26,1 \pm 0,40$ & $28,2 \pm 0,45$ \\
\hline 5 & $24,5 \pm 0,41$ & $26.5 \pm 0,49$ & $39,5 \pm 0,65$ & $42,7 \pm 0,85$ \\
\hline 10 & $37,3 \pm 0,52$ & $40,4 \pm 0,62$ & $85,2 \pm 1,44$ & $922 \pm 2,40$ \\
\hline 20 & $84,1 \pm 1,50$ & $99,9 \pm 2,50$ & $143,0 \pm 2,60$ & $154,7 \pm 3,50$ \\
\hline 30 & $142,1 \pm 3,10$ & $153,8 \pm 4,20$ & $377,1 \pm 12,60$ & $408,0 \pm 11,80$ \\
\hline 60 & $370,5 \pm 16,20$ & $400,9 \pm 18,50$ & $995.5 \pm 19,10$ & $1077.1 \pm 19,50$ \\
\hline
\end{tabular}




\section{Findings}

1) The positive effect of anti-stress drugs and a complex of vitamins on the safety and development of pheasants was revealed.

2) An increase in the safety of the experimental groups of pheasants with the use of an anti-stress drug and a complex of vitamins was established, which was $6.5-20.1 \%$ higher compared to the control group of birds.

3) The mass indicators of pheasants grown in artificial conditions (g) using succinic acid and a complex of vitamins was established.

4) The safety value of pheasants was revealed using succinic acid and a complex of vitamins, which was $7.25-22.5 \%$ higher, and live weight $-8.2 \%$, respectively.

\section{References}

1. Nady EA (1971) A facan es a fogoly intenziv tenyesztese. Budapest, pp. 224.

ISSN: 2574-1241

DOI: 10.26717/BJSTR.2021.36.005891

Shafiga Topchiyeva. Biomed J Sci \& Tech Res

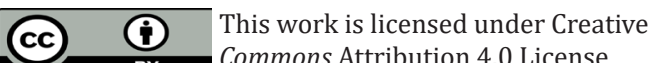

Submission Link: https://biomedres.us/submit-manuscript.php
2. Kuznetsov BA (1972) Breeding M. Forest industry, pp. 178.

3. Kurskova TN (1966) Periodization of postembryonic development of a pheasant. Materials of the VI Baltic Ornithological Conf. Vilnius, p. 61-73.

4. Kuzmina MM (1964) Morpho functional features of the rear chicken limbs. Tr. Institute of Zoology, Academy of Sciences of the Kazakh SSR 24: 152-256.

5. Kuzmina MA (1977) Grouse and pheasant of the USSR. Alma-Ata, pp. 295.

6. Gabuzov OS, Ivanova BC (1976) Prospects for the use of pheasant in artificial wild breeding. In the book: Hunting and nature conservation. M Rosselkhozizdat, p. 87-95.

7. Muhammad Abrar, Shabana Naz, Adnan Qazi, Qazi Adnan Ahm, Arnab Tanveer (2017) Effect of temperature on growth and feed consumption rate of korean ring necked pheasant (Phasianus colchicus). Journal of Entomology and Zoology Studies 5(3): 103-106.

8. Górecki MT, Nowaczewski S, Kontecka H (2012) Body weight and some biometrical traits of ring-necked pheasants (Phasianus colchicus) at different ages. Krakow 60(1-2): 79-84.

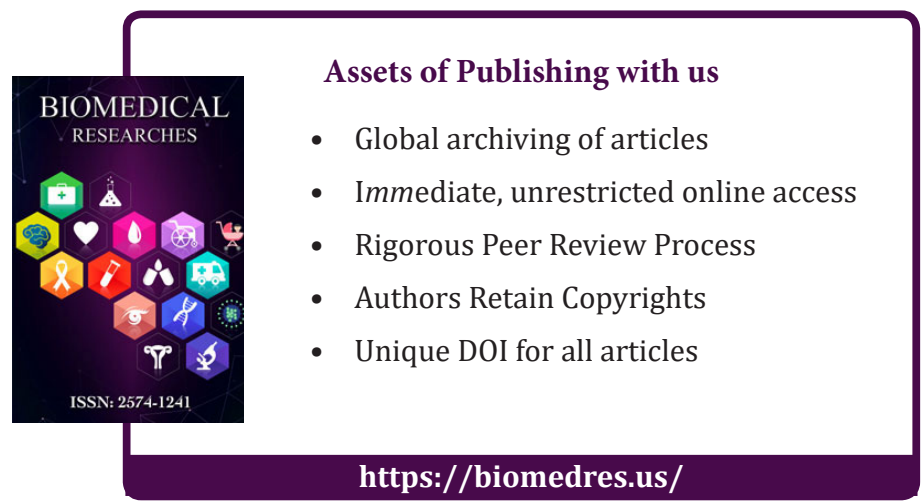

